
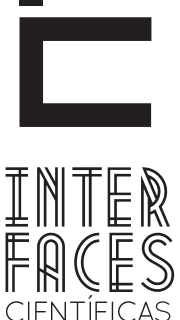

HUMANAS E SOCIAIS

\title{
CULTURA E DESEMPENHO ORGANIZACIONAL: UM ESTUDO COMPARATIVO DOS MODELOS DE ANÁLISE
}

Carla Almeida

Rodrigo Gurian Bortoloto ${ }^{3}$

\author{
Fabíola Dapuzzo Vinhas ${ }^{2}$ \\ Neusa Maria Bastos F. Santos
}

\section{ABSTRACT}

This paper intends to present a comparative table in regards of the main models of analysis of the relation between corporative culture and organizational performance, portrayed by the management literature. The subject has been present in a large number of publications and has aroused the interest of scholars and organizations. For the realization of this paper used the method of content analysis, describing the different methods and pointing out their equalities and relevant characteristics, building this way, in an attempt to synthesize the main aspects in the methods studied aiming to contribute to a better understanding of the subject.

\section{KEYWORDS}

Organizational Culture. Organizational Performance. Analysis of Models.

Cultura Organizacional. Desempenho Organizacional. Análise de Modelos 


\section{RESUMEN}

Este trabajo tiene como objetivo presentar un cuadro comparativo con respecto a algunos de los principales modelos de análisis de la relación entre la cultura corporativa y el desempeño organizativo, relatados por la literatura de gestión. El tema ha estado presente en varias publicaciones y ha suscitado el interés de académicos y organizaciones. Para llevar a cabo este artículo se utilizó el método de análisis de contenido, describiendo los diferentes métodos e indicando sus similitudes y características importantes, convirtiéndose así en un intento de resumir los principales puntos planteados por los métodos estudiados, con el objetivo de contribuir a una mejor comprensión del tema.

\section{PALABRAS CLAVE}

Cultura Organizativa. Desempeño Organizativo. Modelos de Análisis

\section{INTRODUÇÃO}

Desde o início do século XX, ainda que de forma incipiente, a literatura no campo da administração registra alguns autores que mencionaram a influência dos aspectos culturais no estilo de gestão empresarial. Embora não seja recente, é na década de 1980 que o interesse pelo estudo da cultura organizacional ganha importância, como um ponto chave da análise das empresas, por exemplo, na relação entre cultura e desempenho.

Autores como Peters e Waterman (1982) argumentam que a identificação das pessoas com a organização e uma cultura organizacional forte e coesa são fatores que promovem o desempenho e a competitividade. Muitos outros autores têm procurado ratificar esta relação entre cultura e desempenho organizacional, desenvolvendo modelos de análise e realizando pesquisas empíricas (DENISON, 1984; SAFFOLD,
1998; DENISON e MISHRA, 1995; GORDON, 1985; BARNEY, 1986; CALORI e SARNIN, 1991; KOTTER e HESKETT, 1994; MARCOULIDES E HECK, 1993; SANTOS, 1998; OGBONNA e HARRIS, 2000; SORENSEN, 2002).

Dentro desse cenário, o objetivo do presente trabalho é apresentar e descrever os principais modelos de análise da relação entre cultura e desempenho organizacional, possibilitando comparar os aspectos mais relevantes abordados pelos métodos estudados.

0 método de pesquisa utilizado nesse estudo foi análise de conteúdo. A análise de conteúdo se aproxima da técnica de análise documental que objetiva dar forma conveniente e representar de outro modo essa informação, por intermédio de procedimentos de transformação.

\section{CULTURA ORGANIZACIONAL}

Os primeiros a analisar cultura organizacional foram os antropólogos, que buscam definir a cultura por meio dos costumes de uma sociedade e organização. Eles a percebem como uma formação de constru- 
ções sociais. Já os sociólogos vêem a cultura através da elaboração de símbolos, ou seja, observam como certos símbolos são criados e como ocorre a legitimação dos mesmos.

Porém, só a partir da década de 1970 que o termo "cultura organizacional" (ou "cultura corporativa") começou a fazer parte da literatura de administração. Foi Pettigrew (1979) na revista Administrative Science Quartely, o primeiro autor a trazer a tona esse conceito. Para o autor, a organização está em constante movimento, assim como a cultura, pois para ele o homem cria a cultura e a cultura cria o homem (PETTIGREW, 1979). Foi então que o termo cultura começou a ganhar espaço e prestigio no mundo acadêmico.

De acordo com esse autor, a cultura organizacional pode ser definida como um sistema de significados aceitos pública e coletivamente por um dado grupo num dado momento. Este sistema de termos, formas, categorias e imagens interpretam para as pessoas as suas próprias situações (PETTIGREW, 1979).

Nesse contexto, Schein (2001) define cultura organizacional de forma bem abrangente. Para ele, cultura é um conjunto de pressupostos básicos desenvolvidos por um grupo ao aprender a lidar com os problemas de adaptação externa e integração interna e que funcionou bem o suficiente para tornarem-se válidos e repassados a novos membros como a forma correta de agir. Segundo ele a cultura de uma organização pode ser percebida e manifestada em três níveis:

a) Nível dos artefatos: é o ambiente da organização, ou seja, sua configuração, seu layout, maneira de se vestir e de se comportar. E, portanto, "o que se vê, ouve e sente enquanto esta por lá". É um nível de fácil identificação, contudo, seu significado, ou seja, o porquê daquele comportamento leva ao próximo nível. b) Nível dos valores: diz respeito à razão do comportamento das pessoas e são de difícil percepção, pois estão no inconsciente delas.

c) Nível dos pressupostos: são intangíveis e invisíveis e determinam como os membros percebem, sentem e pensam.

Já Hofstede (1990) afirma que a cultura organizacional pode ser percebida a partir de quatro níveis: símbolos, heróis, rituais e valores, sendo que o nível dos símbolos e a manifestação mais superficial e o nível dos valores e a manifestação mais profunda de uma cultura:

a) Símbolos: caracterizam-se por palavras, gestos, figuras ou objetos que trazem um significado e são reconhecidos por pessoas que partilham a mesma cultura.

b) Heróis: são pessoas, vivas ou mortas, reais ou imaginárias, que possuem características altamente valorizadas na cultura cujo comportamento serve de exemplo a ser seguido.

c) Rituais: são atividades coletivas consideradas socialmente essenciais dentro de uma cultura. Como por exemplo, festas de final de ano, cafés da manhã e almoços comemorativos.

d) Valores: são as crenças e conceitos básicos numa organização.

Para chegar a esses níveis, o autor realizou um estudo de caso em 20 unidades de uma empresa (localizadas na Dinamarca e na Holanda) e nas entrevistas efetuou os seguintes questionamentos: "quais são as palavras e termos que somente os membros da organização compreendem?"; "que tipo de pessoas possui o perfil para ter uma carreira meteórica?", "quem você considera como sendo a pessoa que melhor representa a organização?”; "com que periodicidade ocorre confraternizações?", "como as pessoas se comportam 
nestas ocasiões?”, “quais são os eventos celebrados pela organização?” E “que coisas as pessoas gostam de ver acontecer na empresa?", "qual o maior erro que alguém pode cometer?", "que tipos de problemas no trabalho deixam você com insônia?”.

Outro ponto importante a ser destacado na busca pela compreensão da cultura é a diferença entre ela e o chamado clima organizacional. Enquanto a cultura refere-se à identidade, valores e crenças, enraizadas na antropologia e sociologia, o clima refere-se a algo controlado por aspectos ambientais, com raízes na psicologia.

A cultura desempenha diversos papéis dentro de uma organização. Nesse sentido O'reilly, Chatman e
Caldwell (1991), citam cinco funções da cultura. A primeira refere-se a definir fronteiras, distinguir a organização de seu ambiente. A segunda é proporcionar uma identidade para os membros que fazem parte daquela organização. A terceira é gerar um comprometimento com os objetivos da organização. A quarta diz respeito a criar uma estabilidade do sistema social e a quinta serve como instrumento de controle que orienta as atitudes dos membros.

Quanto à discussão sobre como surge a cultura organizacional em uma empresa, há muito dissenso. Porém, Schein (2001) diz que a importância dos fundadores no estabelecimento da cultura é um dos poucos assuntos que há consenso.

\subsection{TIPOLOGIAS CULTURAIS}

Cabe destacar que nenhuma tipologia corresponde à realidade, no entanto, ela ajuda na compreensão da cultura de uma organização. Santos (2000) evidencia a vantagem de se usar as tipologias culturais, pois possuem "habilidades de examinar empiricamente a extensão na qual os elementos de uma cultura são congruentes". Além de "permitir generalizar sobre uma dada classe de organizações e porque contribuem para explicar as diferenças entre organizações”. Os próxi-

mos parágrafos apresentam as tipologias mais utilizadas para identificar culturas organizacionais.

Segundo Santos (2000) o mérito dessa tipologia é "que ela serve para delimitar a amplitude teórica e desenvolver enunciados singularmente úteis a respeito de um conjunto mais amplo de organizações". Na figura 1 estão identificadas as principais características do modelo:

Figura 1 - Tipologias Culturais

\section{Cultura de tarefa:}

- orientada para trabalho ou projetos;

- estrutura em rede;

- $\quad$ ênfase no poder do especialista;

- estimulo ao trabalho em equipe;

- adaptável;

- difícil controle.

\section{Cultura da pessoa:}

- valorização do talento;

- valorização da habilidade;

- indivíduo como ponto central;

- galáxia de estrelas individuais;

- desprezo as normas rígidas. 


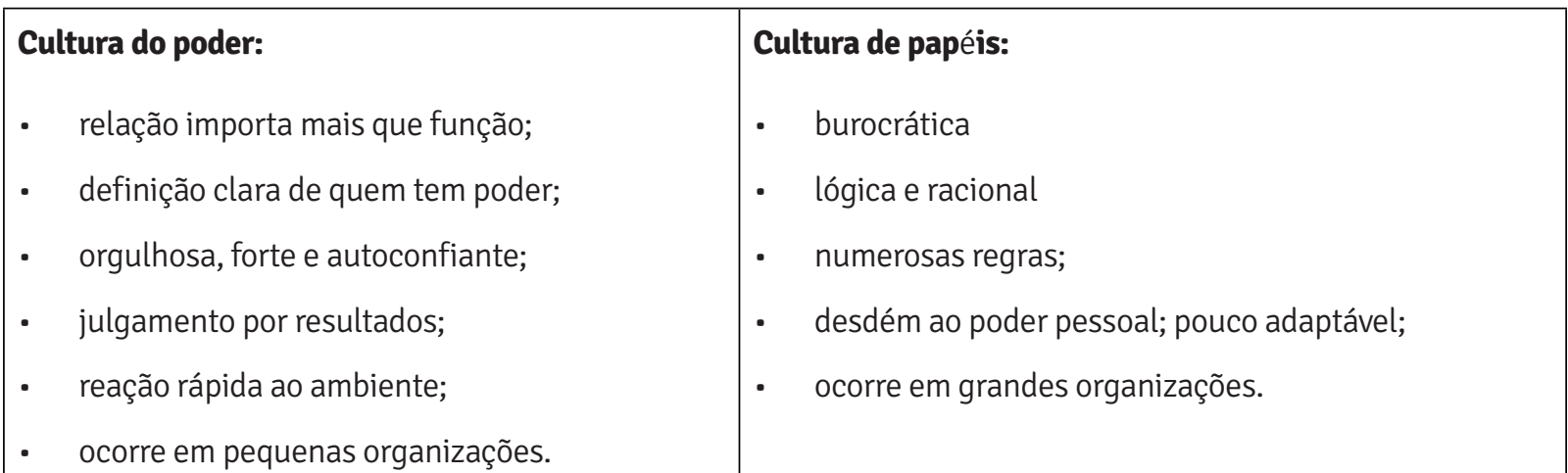

Fonte: elaborado pelos autores com base em Santos, 2000

Com base nessa análise, os autores identificaram o grau de risco das atividades da empresa, com a velocidade de retorno referente ao acerto das decisões. A

Figura 2 - Risco e retorno figura 2 aponta as principais características das tipologias propostas:

\begin{tabular}{|c|c|}
\hline $\begin{array}{l}\text { Empresas de alto risco e retorno rápido: } \\
\text { - } \quad \text { grande aceitação de riscos; } \\
\text { - } \quad \text { acirrada competição interna; } \\
\text { - } \quad \text { elnfase na criatividade; } \\
\text { - } \quad \text { ex: empresas de publicidade, televisão, cinema, etc. }\end{array}$ & $\begin{array}{l}\text { Empresas de alto risco e retorno lento: } \\
\text { - a importância de tomar a decisão certa gera um } \\
\text { clima de ponderação; } \\
\text { - o mundo move-se em meses e em anos e não em } \\
\text { dias; } \\
\text { - os valores se focam no futuro e na importância de } \\
\text { construí-lo }\end{array}$ \\
\hline $\begin{array}{l}\text { Empresas de baixo risco e retorno rápido: } \\
\text { - o sucesso vem com a persistência; } \\
\text { - } \quad \text { os valores são focados nas necessidades de clientes; } \\
\text { - } \quad \text { cultura encoraja a um alto grau de atividade, mas relativamente pequenos; } \\
\text { - ex: imobiliárias, distribuidores, etc. }\end{array}$ & $\begin{array}{l}\text { Empresas de baixo risco e retorno lento: } \\
\text { - também chamada de cultura de processo; } \\
\text { - a falta de feedback faz com que os empregados se } \\
\text { foquem no como e não no que; } \\
\text { - o mais comum dos eventos torna-se assunto para } \\
\text { um oficio; } \\
\text { - valores focados em perfeição técnica e rigor for- } \\
\text { mal. }\end{array}$ \\
\hline
\end{tabular}

Fonte: elaborada pelos autores com base em SANTOS, 2000 
Deal e Kennedy (1982) também consideram quatro tipos culturais, para eles, o que influencia a cultura individualmente é o ambiente social em que a empresa opera. Donnely (1984) observa a relação da cultura com o uso do planejamento, como resultado da personalidade da gerência. Para tanto identifica três tipos culturais:

Figura 3 - Tipos Culturais

\begin{tabular}{|l|l|}
\hline \multicolumn{1}{|c|}{ Tipos culturais } & \multicolumn{1}{c|}{ Características } \\
\hline Cultura Excelente & O planejamento e respeitado pela maioria da organização \\
\hline Cultura Fuzzy & Mudança constante com processo decisório baseado em tentativa e erro \\
\hline Cultura Vaga & Estabilidade interna fruto de alta regulamentação ou maturidade \\
\hline
\end{tabular}

Fonte: elaborado pelos autores com base em Freitas, 1991

Quinn (1984 apud SANTOS, 1998) desenvolveu o modelo chamado Competing value Model que assume que as organizações podem ser caracterizadas de acordo com seus traços culturais comuns. Também conhecido como Tipologia Cultural de Quinn, o modelo é caracterizado por quatro tipos de cultura: grupal, inovativa, hierárquica e racional, representadas na figura 04.

Figura 4 - Tipologia Cultural de Quinn

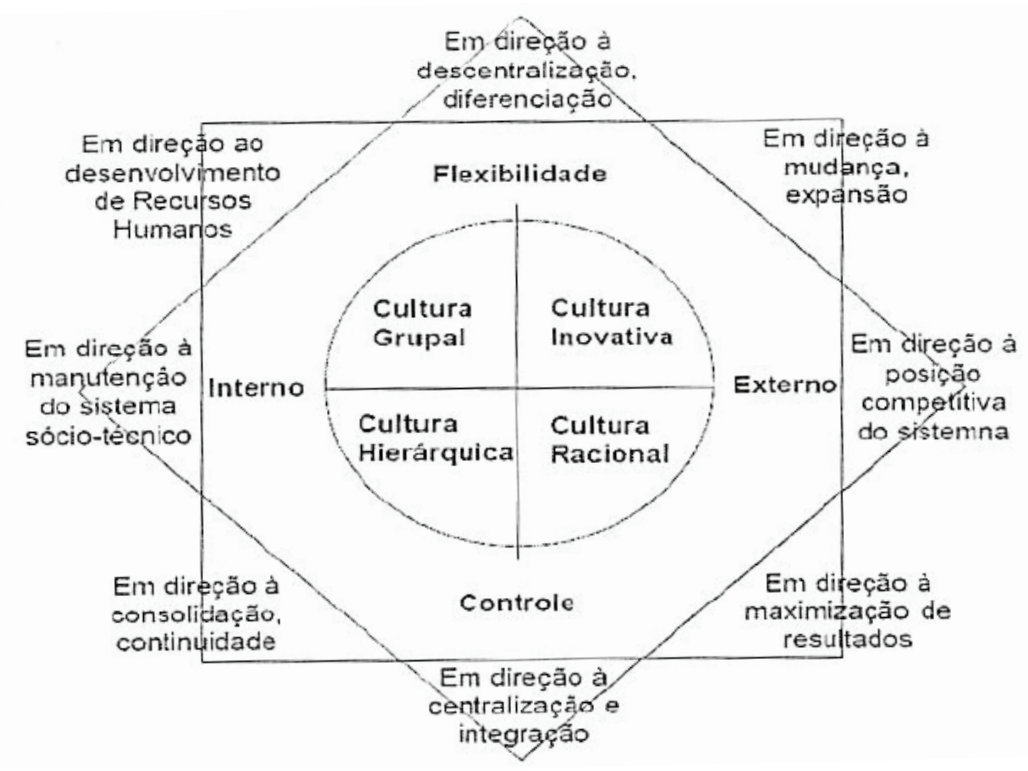

Fonte: SANTOS, 1998 (p. 57). 
A primeira dimensão está relacionada ao enfoque organizacional e pode refletir desde o ambiente interno até o ambiente externo. A segunda dimensão está relacionada à estrutura organizacional e aborda o controle, a estabilidade, bem como a flexibilidade e a mudança.

A tipologia clã consiste no desenvolvimento de recursos humanos e valoriza, principalmente, a participação dos membros que estão envolvidos com a organização no processo decisório, bem como o trabalho em equipe. A tipologia inovativa é permeada por pressupostos de mudança e flexibilidade e os fatores chaves para a motivação incluem crescimento, estí-

\section{DESEMPENHO ORGANIZACIONAL}

Antes de relacionar cultura e desempenho organizacional é preciso definir o que é desempenho. Barney (1986) apresenta dois conceitos para desempenho. 0 primeiro diz respeito à comparação entre o valor que uma organização gera usando seus ativos com o valor que os proprietários desses ativos esperam receber. Já o segundo conceito utiliza uma visão de múltiplas partes interessadas, ou seja, o desempenho é medido conforme a percepção de cada stakeholder sobre a organização. Esse conceito gera, portanto, diferentes percepções de desempenho, pois cada parte interessada vai olhar o que the interessa. Por exemplo, um cliente pode atribuir um bom desempenho para uma empresa que oferece produtos de qualidade e preços baixos, contudo, a mesma empresa pode gerar uma percepção de desempenho insatisfatório para os acionistas que esperam maiores retornos.

Esse entendimento referente às partes interessadas gera diferentes medidas de desempenho. Surgem então, as medidas de desempenho financeiro e econômico (associada aos acionistas), de qualidade e preços (associada aos clientes), de responsabilidade social (associada à comunidade/sociedade), dentre mulo, diversificação e criatividade na tarefa (SANTOS, 1998). A tipologia hierárquica demonstra os valores e normas associadas à burocracia e norteadas por pressupostos de estabilidade. A tipologia racional busca alcançar melhores resultados organizacionais por meio da competitividade e produtividade e é permeada pela crença de que quanto maior for o desempenho e os resultados, maior a recompensa.

Como um referencial teórico para o estudo da cultura organizacional, o Competing Value Model representa uma alternativa diferente do enfoque qualitativo, que tem caracterizado a realização da maioria das pesquisas em cultura (SANTOS, 1998).

outras medidas. Cabe destacar que as medidas de desempenho econômico e financeiro são as mais comuns para se avaliar o desempenho das organizações.

Freitas (1991) cita que alguns poucos autores não acreditam que a cultura possa influenciar o desempenho e enumera algumas razões para isso:

a) Dificuldade de isolar a variável cultura das demais que podem influenciar o desempenho;

b) Métodos de pesquisa são questionados e podem não ser válidos;

c) Dificuldade consensual devido a questões conceituais.

Entender como as empresas caracterizam ou mudam suas estruturas internas é importante para classificar e compreender o desempenho. 0 caráter da organização pode ser compreendido por dois componentes principais: Relacionamento Organização-Ambiente e Componentes de Desenho Interno. 
Os componentes de desenho interno podem ser vistos na figura 5 , que está baseada fortemente na teoria dos sistemas abertos, que identifica as organizações como parte integrante de um ambiente maior (CUMMINGS e WORLEY, 2001).

Um conceito chave desta teoria é a congruência ou encaixe dos componentes. As organizações precisam integrar os cinco componentes, de tal forma que cada um possa reforçar o comportamento necessário dos outros componentes para atingir os objetivos estratégicos da organização. A Estratégia define como uma organização utilizará seus recursos para ganhar vantagem competitiva no ambiente. Ambiente consiste dos elementos e forças externas que afetam a habilidade da organização atingir seus objetivos estratégicos.

0 ambiente possui a característica de variar desde uma situação estática até uma situação dinâmica. Para se adaptar a ambientes mais dinâmicos, as orga-

\section{CULTURA E DESEMPENHO: MODELOS DE ANÁ- LISE}

A maioria dos autores acredita que a cultura pode sim afetar o desempenho de uma organização, posição que também é assumida pelos autores no presente trabalho. Entre os autores que concordam com a afirmação acima se destacam: Denison (1984), Denison e Mishra (1995), Gordon (1985), Barney (1986), Calori e Sarnin (1991), Kotter e Heskett (1994), Marcoulides e Heck (1993), Ogbonna e Harris (2000), Sorensen (2002) e no Brasil a pesquisa de Santos (1998).

Nos estudos dessa relação existem duas vertentes: uma que trata a cultura como variável independente e desempenho como variável dependente, onde se baseiam os trabalhos de Denison (1984), Gordon nizações precisam de um desenho com componentes mais flexíveis para promover respostas mais rápidas. No caso de ambientes mais estáticos, as organizações utilizam um desenho com componentes mais formais para responder de forma padronizada.

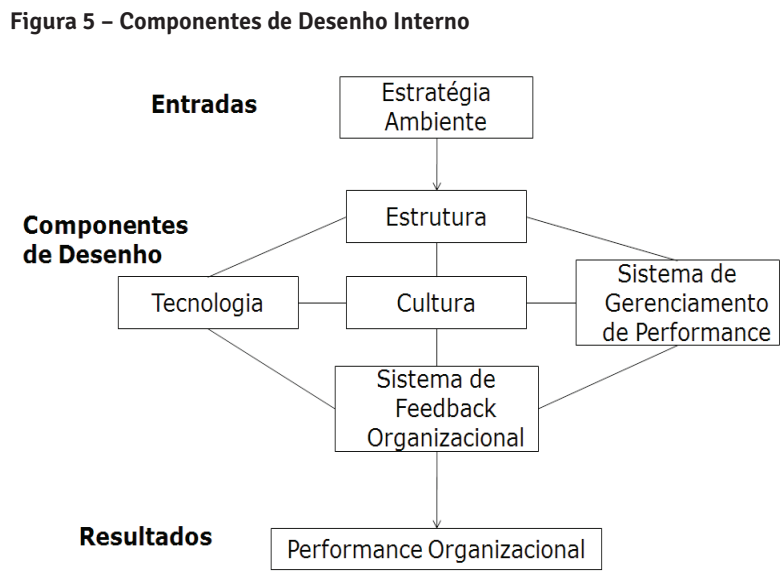

Fonte: CUMMINGS e WORLEY, 2001

(1985) e outros pesquisadores, e outra que considera o desempenho como variável de independente e fator determinante dos atributos da cultura organizacional, que nesse caso passa a ser variável dependente. Porém, os resultados obtidos nesse inverso foram insatisfatórios para apoiar a segunda vertente (SANTOS, 1998). 


\subsection{DENISON [1984]}

0 autor relacionou indicadores de desempenho financeiro e da cultura organizacional de 34 empresas de setores diferentes. Para medir o desempenho utilizou dados de cinco anos obtidos através das médias do índice retorno sobre investimento e lucro sobre vendas. Já para coletar dados sobre cultura aplicou um ques-

\subsection{GORDON [1985]}

Numa análise mais profunda, foi medido por três anos, a relação entre cultura e desempenho, estudando $63 \mathrm{em}$ presas. Empresas que ele denominou de estáveis (por trabalhar em ambiente estável, como empresas de eletricidade e gás), dinâmicas (fabricante de produtos altamente competitivos e que utilizam em seu processo produtivo elementos de alta tecnologia, como telecomunicações e internet) e empresas financeiras (bancos e seguradoras). tionário com 120 questões aplicado a 43 mil empregados num período de dez anos. As respostas referentes a esse questionário foram agrupadas em 22 fatores culturais. 0 autor inferiu, com base no seu estudo, que empresas com uma cultura mais participativa tinham um retorno sobre vendas e investimento maiores.

Figura 6 - Dimensões Culturais

\begin{tabular}{|c|c|}
\hline Dimensões culturais & Conteúdo \\
\hline Clareza de direção & Objetivos claros e planos compatíveis \\
\hline Alcance organizacional & Matas ousadas e inovadoras \\
\hline Integração & Operar de maneira coordenada, interdependência horizontal \\
\hline Contato administração superior & Interdependência vertical \\
\hline Encorajar iniciativa pessoal & Liberdade de agir, inovar e assumir riscos \\
\hline Resolução de conflitos & Encorajar discussão de conflito e criticas abertamente \\
\hline Clareza de desempenho & Tornar claras as expectativas de desempenho da companhia \\
\hline Ênfase no desempenho & $\begin{array}{l}\text { Expectativas de altos níveis de desempenho e responsabilidade pessoal } \\
\text { dos empregados em atingi-los }\end{array}$ \\
\hline Orientação para a ação & $\begin{array}{l}\text { Periodicidade das decisões tomadas, senso de urgência em agir Percep- } \\
\text { ção dos funcionários sobre como estão sendo pagos, }\end{array}$ \\
\hline Compensação & $\begin{array}{l}\text { Percepção dos funcionários sobre como estão sendo pagos, com- } \\
\text { petitivamente e com justiça. }\end{array}$ \\
\hline Desenvolvimento de recursos humanos & Oportunidade para crescer e desenvolver-se na companhia \\
\hline
\end{tabular}

Fonte: GORDON, 1985 In: FREITAS, 1991

Para mediro desempenhoanalisou a rentabilidade organizacional no ano da pesquisa e mais dois anos subsequentes. Para as empresas que estavam inseridas em um ambiente altamente competitivo, também, foi levado em conta o crescimento de suas receitas no período analisado. Já para avaliar a cultura mediu a percepção do corpo gerencial sobre o sistema de valores da empresa, com questões que englobaram 11 dimensões culturais, conforme a figura 6 . 
A pesquisa demonstra que a maneira como a empresa é organizada e a forma de interação das pessoas dentro da organização, influem na cultura, portanto, a cultura é uma variável que afeta o desempenho or-

\subsection{BARNEY [1986]}

Este autor estudou a relação entre cultura e desempenho e concluiu que a cultura só pode influenciar o desempenho se for passível de mensuração, rara e não imitável. Ele analisou quais as características uma cultura organizacional deve possuir para se tornar fonte de vantagem competitiva sustentável frente aos concorrentes, sendo então geradora de desempenho financeiro superior à média, resumindo em três:

a) Valiosa: a cultura deve adicionar valor financeiro à organização;

\subsection{CALORI E SARNIN [1991]}

Para estes autores a cultura de uma organização emerge através de pressupostos básicos, valores, normas de comportamento e de suas manifestações mais visíveis e diretas, tais como os símbolos (linguagem, rituais, mitos, arquitetura etc.) e as práticas gerenciais (sistemas de recrutamento e seleção, sistemas de avaliação e recompensa, relações com clientes, competidores e com o ambiente social, entre outros). Para estudar a relação entre cultura organizacional e desempenho econômico os autores realizaram uma pesquisa de campo na França, com ganizacional. Por fim, concluiu que empresas com desempenho superior a média administravam os conflitos de forma mais transparente e aberta. Ou seja, a cultura interferiu no resultado financeiro.

b) Rara: a cultura não deve possuir características comuns a outras organizações;

c) Imitável: as organizações não podem buscar imitar outras culturas, pois terão desvantagens frente as organização a serem imitadas.

Baseou suas conclusões em um estudo empírico que realizou com as seguintes empresas: IBM, HP, Procter \& Gamble e McDonald's. Todas as empresas analisadas apresentaram culturas fortes, os três atributos propostos e possuíam um ótimo desempenho.

cinco empresas de mercado maduro e com estratégias de diferenciação.

Os autores concluíram que possuir atributos culturais claros está associado ao crescimento da empresa e que valores como realização pessoal, espírito de equipe, ouvir os outros, responsabilidade, confiança, abertura para o ambiente, adaptação, antecipação, qualidade e consistência correspondem a práticas gerenciais que são positivamente relacionadas com 0 crescimento de uma organização.

\subsection{MARCOULIDES E HECK [1993]}

Já estes autores propõem um modelo que relaciona cinco dimensões, sendo elas: estrutura da organização (relações e processos); valores organizacionais (princípios, ideologias e valores); organização de tarefa (estratégias, políticas e ações); clima organizacional (percepções do ambiente de trabalho) e atitudes e 
objetivos pessoais (preocupações sociais e políticas). Essas cinco dimensões contam com um total de 26 variáveis que comporiam a cultura e o desempenho da organização medido em termos de ganhos de capital $x$ custos pelas seguintes variáveis: vendas ou faturamento; penetração de mercado; lucratividade operacional e retorno de investimento. A figura 7representa o esquema desse modelo.

Figura 7 - Modelo de relação cultura e desempenho

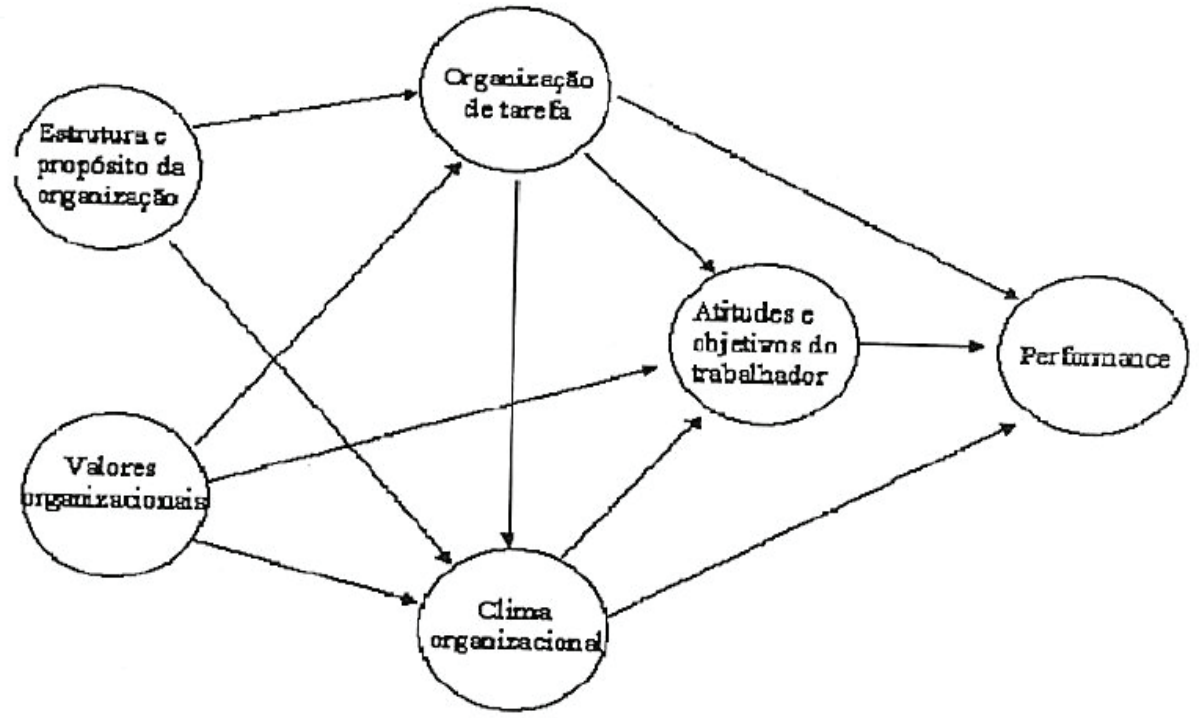

Fonte: Adaptado de MARCOULIDES e HECK, 1993, p. 209-225.

Para testar o modelo Marcoulides e Heck (1993) estudaram 26 empresas de diversos setores nos Estados Unidos. Os participantes do estudo responderam a uma entrevista e questionários que continham perguntas relativas às variáveis de percepção da cultura organizacional. Além do questionário, foram coletados dados sobre a produtividade e documentos financeiros.

Os autores concluíram que os resultados são consistentes com as pesquisas que sugerem as variáveis

\subsection{KOTTER E HESKETT [1994]}

No trabalho destes autores foi realizada uma pesquisa bem completa com 207 empresas de 22 setores diferentes. Devido ao grande volume de empresas que associam cultura organizacional e previsões de desempenho organizacional. Porém, para eles é difícil afirmar a relação positiva entre desempenho e cultura organizacional, já a complexidade do desenvolvimento dos processos organizacionais não permite aos líderes das empresas identificarem claramente a relação de causa e efeito entre desempenho e cultura corporativa.

eles dividiram a pesquisa em quatro partes. A primeira etapa analisou as 10 maiores empresas em 22 indústrias diferentes nos EUA, a fim de avaliar a cultura e 
o desempenho em longo prazo. A segunda etapa buscou avaliar 22 das 207 empresas originais para ponderar com maior profundidade a relação entre cultura e desempenho. A terceira etapa foi mais especifica e analisou 20 empresas que tiverem desempenho econômico ruim, prejudicadas por sua cultura. A quarta e última etapa analisou 10 empresas que mudaram suas culturas e obtiveram benefícios econômicos.

Os autores avaliaram a cultura por meio de três métodos, verificaram a força cultural, as culturas estrategicamente ajustáveis e as culturas adaptativas. Utilizaram essas três metodologias para avaliar a cultura por acreditarem que nenhum modelo é inteiramente satisfatório, porém, não há nenhum conflito caso sejam combinados. A figura 8 compara os três modelos utilizados.
Utilizaram três métodos para mensurar o desempenho das organizações no período de 1977 a 1988 Avaliaram: aumento anual médio de renda liquida (mais vulnerável, pois pode ser distorcido por processos de fusões e aquisições), lucro médio anual sobre investimento, aumento anual médio do preço das ações.

Após inúmeras análises e pesquisas, os autores concluíram que a cultura pode impactar no desempenho em longo prazo de uma organização. Chegaram a essa conclusão, pois comprovaram que culturas que enfatizam todos os interessados e que possuem lideranças fortes superam as que não possuem esses traços culturais.

Figura 8 - Comparação

\begin{tabular}{|c|c|c|c|}
\hline & Culturas fortes & $\begin{array}{c}\text { Culturas estrategicamente } \\
\text { adaptáveis }\end{array}$ & Culturas adaptativas \\
\hline $\begin{array}{l}\text { O que } \\
\text { propõe o } \\
\text { modelo }\end{array}$ & $\begin{array}{l}\text { Mostra o papel que normas e va- } \\
\text { lores desempenham para alinhar, } \\
\text { motivar e controlar um grupo } \\
\text { de pessoas e tarefas difíceis em } \\
\text { organizações complexas. }\end{array}$ & $\begin{array}{l}\text { Mostra a importância de ter práti- } \\
\text { cas que se ajustam as condições } \\
\text { específicas nas quais opera uma } \\
\text { cultura. }\end{array}$ & $\begin{array}{l}\text { Salienta valores e comporta- } \\
\text { mentos } \\
\text { específicos que ajudam a } \\
\text { empresa e sua cultura a se } \\
\text { adaptarem as mudanças. }\end{array}$ \\
\hline Vantagens & $\begin{array}{l}\text { Se a direção que a cultura está } \\
\text { tomando for boa, uma cultura } \\
\text { forte pode beneficiar o desempe- } \\
\text { nho da empresa. }\end{array}$ & $\begin{array}{l}\text { Ajusta-se ao conteúdo e estratégia } \\
\text { organizacional. }\end{array}$ & $\begin{array}{l}\text { Ajuda a organização e prever e } \\
\text { se adaptar às mudanças. }\end{array}$ \\
\hline $\begin{array}{l}\text { Desvanta- } \\
\text { gens }\end{array}$ & $\begin{array}{l}\text { Direção errada da cultura forte e } \\
\text { dificuldades de encontrar a cau- } \\
\text { sa e o efeito (a cultura forte que } \\
\text { provoca um bom desempenho ou } \\
\text { vice e versa). }\end{array}$ & $\begin{array}{l}\text { Explica desempenhos excelentes } \\
\text { em curto prazo e não conseguem } \\
\text { verificar o longo prazo. }\end{array}$ & $\begin{array}{l}\text { Não explica por que as orga- } \\
\text { nizações que não possuem } \\
\text { caráter inovador e empreen- } \\
\text { dedor podem obter um bom } \\
\text { desempenho. }\end{array}$ \\
\hline
\end{tabular}

Fonte: elaborado com base em KOTTER e HESKETT, 1994.

A figura 9 compara força cultural e aumento de desempenho. 
Figura 9 - Comparação força cultural e desempenho

\begin{tabular}{|lll|}
\hline CULTURA FORTE & \multicolumn{1}{c|}{ CULTURA FRACA } & \multicolumn{1}{c|}{ (período de 11 anos) } \\
$682 \%$ & $166 \%$ & AUMENTO NOS RENDIMENTOS \\
$282 \%$ & $36 \%$ & AUMENTO DA FORÇA DE TRABALHO \\
$901 \%$ & $74 \%$ & AUMENTO NO PREÇO DAS AÇÕES \\
$756 \%$ & $1 \%$ & MELHOR RENDIMENTO LÍQUIDO \\
\hline
\end{tabular}

Fonte: elaborado pelos autores com base em KOTTER e HESKETT, 1994.

\subsection{OGBONNA E HARRIS [2000]}

Para estes autores foi fundamental analisar a relação entre liderança, cultura e desempenho, estudando as relações entre liderança e desempenho e entre cultura e desempenho independentemente. Para isso, eles estudaram uma amostra de 322 empresas de setores variados do Reino Unido. 0 desempenho econômico-financeiro de curto prazo foi mensurado por meio de questionário e de longo prazo foi medido por dados de satisfação de cliente, crescimento e volume de vendas, participação de mercado e vantagem competitiva.

A cultura organizacional foi classificada de acordo com tipologia de Quinn (competitiva, inovativa, burocrática e de comunidade) e os tipos de liderança considerados foram: participativa, instrumental e suporte. A análise de dados foi realizada por meio de instrumentos estatísticos (correlações e regressões).

Eles concluíram que os estilos de liderança não estão diretamente associados ao desempenho organizacional. Quanto aos resultados sobre a relação entre desempenho organizacional e tipos de cultura, o estudo evidenciou uma relação positiva entre o tipo de cultura competitiva e inovativa e uma relação negativa entre o tipo comunidade e burocrática.

\subsection{SORENSEN [2002]}

Este autor estudou a relação entre culturas fortes e a variação do desempenho organizacional. Para ele essa relação depende de como as culturas fortes afetam a aprendizagem organizacional, de acordo as mudanças internas e externas. A hipótese do trabalho de Sorensen (2002) é que as empresas de cultura forte superam a mudanças, mas encontram dificuldades em ambientes mais voláteis.

Em seu estudo, o autor utilizou os dados da pesquisa de Kotter e Heskett (1994) sobre a força da cultura corporativa. As variáveis que mediram o desempenho econômico-financeiro foram: retorno sobre os investimentos (ROI) e fluxo de caixa operacional entre 1979 e 1984. Os resultados das análises demonstraram que nas empresas de cultura forte o desempenho foi menos variável em ambientes estáveis, entretanto em ambientes voláteis os benefícios de uma cultura forte desaparecem. 


\subsection{Santos (1998)}

A autora brasileira buscou analisar se a força cultural esta associada ao desempenho organizacional e, ainda, se empresas com culturas fortes podem evidenciar melhor desempenho do que aquelas com cultura fraca. Para isso estudou 13 empresas do setor têxtil e para medir o desempenho baseou-se no tra- balho do Prof. Dante Matarazzo, que analisa índices financeiros e aspectos econômicos, utilizando dados de 1988, 1989 e 1990.

A figura 10 indica a relação entre desempenho e força cultural:

Figura 10 - Relação Força cultural e Desempenho

\begin{tabular}{|lccc|}
\hline \multirow{2}{*}{ Tipo Cultura } & Empresa & Desempenho & Força Cultural \\
\hline \multirow{3}{*}{ Perfil do Grupo 1 } & L & BOM & 15,60 \\
\cline { 2 - 4 } Culturas Fortes & E & BOM & 15,13 \\
\cline { 2 - 4 } & C & BOM & 14,69 \\
\cline { 2 - 4 } & A & BOM & 14,64 \\
\hline \multirow{3}{*}{ Perfil do Grupo 2 } & B & MAU & 14,37 \\
& N & MAM & 14,26 \\
\hline \multirow{3}{*}{ Culturas Fracas } & D & BOM & 13,84 \\
& M & MAU & 13,59 \\
& I & BOM & 13,29 \\
& H & MAU & 13,14 \\
& J & MAU & 12,59 \\
& G & MAU & 12,35 \\
\hline
\end{tabular}

Fonte: SANTOS, 1998.

Posteriormente, para avaliar a cultura das empresas do setor, aplicou um questionário com 24 proposições capazes de gerar perfis que representassem diferentes padrões culturais da organização, conforme a tipologia cultural de Quinn (Competing Value Model).
Através do seu estudo a autora pôde inferir que empresas que possuíam um equilíbrio entre os quatro quadrantes do modelo utilizado, ou seja, aquelas com culturas fortes possuíam também melhores desempenhos econômico-financeiros.

As empresas que mais incorporavam as quatro características dos tipos culturais eram consideradas fortes. 


\section{ANÁLISE COMPARATIVA DOS MODELOS E CONSIDERAÇÕES FINAIS}

A figura 11 apresenta uma síntese dos aspectos considerados como mais relevantes dentro dos modelos de análise da relação entre cultura e desempenho.

Tabela 11 - Comparativo final entre métodos

\begin{tabular}{|c|c|c|c|c|}
\hline Autor & Título do Trabalho & Avaliação da cultura & $\begin{array}{l}\text { Avaliação do } \\
\text { desempenho }\end{array}$ & Conclusões \\
\hline Denison, 1984 & $\begin{array}{l}\text { Bringing corporate } \\
\text { culture to the bot- } \\
\text { tom line. }\end{array}$ & $\begin{array}{l}\text { Aplicou um questioná- } \\
\text { rio com } 120 \text { questões } \\
\text { a } 43 \text { mil empregados } \\
\text { num período de } 10 \\
\text { anos. As respostas fo- } \\
\text { ram agrupadas em } 22 \\
\text { fatores culturais. }\end{array}$ & $\begin{array}{l}\text { Analisou dados de cin- } \\
\text { co anos obtidos através } \\
\text { das medidas do índice } \\
\text { retorno sobre o investi- } \\
\text { mento (ROI) e lucro so- } \\
\text { bre vendas. }\end{array}$ & $\begin{array}{l}\text { Concluiu que empre- } \\
\text { sas com uma cultura } \\
\text { mais participativa ti- } \\
\text { nham maior retorno } \\
\text { sobre vendas e investi- } \\
\text { mentos. }\end{array}$ \\
\hline Gordon, 1985 & $\begin{array}{l}\text { The relationship of } \\
\text { corporate culture } \\
\text { to industry sector } \\
\text { and corporate per- } \\
\text { formance }\end{array}$ & $\begin{array}{l}\text { Mediu a percepção do } \\
\text { corpo gerencial sobre } \\
\text { o sistema de valores } \\
\text { da empresa com ques- } \\
\text { tões que englobaram } \\
11 \text { dimensões cultu- } \\
\text { rais. }\end{array}$ & $\begin{array}{l}\text { Analisou a rentabili- } \\
\text { dade da empresa no } \\
\text { ano da pesquisa e mais } \\
\text { dois anos subsequen- } \\
\text { tes. Para as empresas } \\
\text { que estavam em um } \\
\text { ambiente altamente } \\
\text { competitivo também foi } \\
\text { considerado o cresci- } \\
\text { mento de suas receitas. }\end{array}$ & $\begin{array}{l}\text { Concluiu que empre- } \\
\text { sas com desempenho } \\
\text { superior à média admi- } \\
\text { nistravam os conflitos } \\
\text { de forma transparente } \\
\text { e aberta. Ou seja, a } \\
\text { cultura organizacional } \\
\text { interferiu favoravel- } \\
\text { mente no resultado } \\
\text { financeiro. }\end{array}$ \\
\hline Barney, 1986 & $\begin{array}{l}\text { Organizational } \\
\text { Culture: Can it be } \\
\text { a source of sus- } \\
\text { tained competitive } \\
\text { advantage? }\end{array}$ & $\begin{array}{l}\text { Criou três atributos } \\
\text { para avaliar a cultura } \\
\text { valiosa, rara e imitá- } \\
\text { vel. }\end{array}$ & $\begin{array}{l}\text { Analisou se as empre- } \\
\text { sas IBM, HP, Procter \& } \\
\text { Gamble e McDonald's } \\
\text { possuíam os três atribu- } \\
\text { tos para gerarvantagem } \\
\text { competitiva sustentável } \\
\text { frente aos concorrentes } \\
\text { e gerar resultados fi- } \\
\text { nanceiros maiores. }\end{array}$ & $\begin{array}{l}\text { Concluiu que todas as } \\
\text { empresas analisadas } \\
\text { apresentaram culturas } \\
\text { fortes, os três atributos } \\
\text { propostos e possuíam } \\
\text { ótimo desempenho. }\end{array}$ \\
\hline
\end{tabular}




\begin{tabular}{|c|c|c|c|c|}
\hline Autor & Título do Trabalho & Avaliação da cultura & $\begin{array}{l}\text { Avaliação do } \\
\text { desempenho }\end{array}$ & Conclusões \\
\hline $\begin{array}{l}\text { Calori e Samin, } \\
1991\end{array}$ & $\begin{array}{l}\text { Coporate culture } \\
\text { and economic per- } \\
\text { formance: A french } \\
\text { study }\end{array}$ & $\begin{array}{l}\text { Avaliaram a cultura de } \\
\text { cinco empresas fran- } \\
\text { cesas, entrevistando } \\
250 \text { indivíduos e anali- } \\
\text { sando seus pressupos- } \\
\text { tos básicos, valores, } \\
\text { normas de compor- } \\
\text { tamento e suas ma- } \\
\text { nifestações mais visí- } \\
\text { veis, os símbolos e as } \\
\text { práticas gerenciais. }\end{array}$ & $\begin{array}{l}\text { Analisaram o retorno } \\
\text { sobre investimento e } \\
\text { crescimento nas vendas } \\
\text { durante três anos. }\end{array}$ & $\begin{array}{l}\text { Concluíram que pos- } \\
\text { suir atributos culturais } \\
\text { claros está associa- } \\
\text { do ao crescimento da } \\
\text { empresa e que valores } \\
\text { como realização pes- } \\
\text { soal, espírito de equi- } \\
\text { pe, ouvir os outros, } \\
\text { dentre outros, corres- } \\
\text { pondem a práticas ge- } \\
\text { renciais que são positi- } \\
\text { vamente relacionadas } \\
\text { com o crescimento do } \\
\text { desempenho. }\end{array}$ \\
\hline $\begin{array}{l}\text { Marcoulides e } \\
\text { Heck, } 1993\end{array}$ & $\begin{array}{l}\text { Culture and perfor- } \\
\text { mance proposing } \\
\text { and testing model }\end{array}$ & $\begin{array}{l}\text { Propuseram um mo- } \\
\text { delo que relaciona } \\
\text { cinco dimensões, sen- } \\
\text { do elas: estrutura da } \\
\text { organização, valores, } \\
\text { organização da tarefa, } \\
\text { clima, atitudes e obje- } \\
\text { tivos pessoais. Essas } \\
\text { cinco dimensões con- } \\
\text { tam com um total de } \\
26 \text { variáveis que for- } \\
\text { mam a cultura. }\end{array}$ & $\begin{array}{l}\text { Mediram o desempenho } \\
\text { em termos de ganhos } \\
\text { de capital x custos pe- } \\
\text { las seguintes variáveis: } \\
\text { vendas ou faturamento, } \\
\text { penetração de mercado, } \\
\text { lucratividade operacio- } \\
\text { nal e retorno de investi- } \\
\text { mento. }\end{array}$ & $\begin{array}{l}\text { Fizeram correlações } \\
\text { estatisticamente signi- } \\
\text { ficativas entre cultura } \\
\text { e desempenho organi- } \\
\text { zacional, entretanto é } \\
\text { difícil afirmar a causa } \\
\text { e efeito entre as variá- } \\
\text { veis. }\end{array}$ \\
\hline $\begin{array}{l}\text { Kotter e Hesket, } \\
1994\end{array}$ & $\begin{array}{l}\text { A cultura corpora- } \\
\text { tiva e o desempe- } \\
\text { nho empresarial }\end{array}$ & $\begin{array}{l}\text { Avaliaram a cultura } \\
\text { por meio de três mé- } \\
\text { todos, verificaram a } \\
\text { força cultural, as cul- } \\
\text { turas estrategicamen- } \\
\text { te ajustáveis e as cul- } \\
\text { turas adaptativas. }\end{array}$ & $\begin{array}{l}\text { Avaliaram: aumento } \\
\text { anual de renda líquida } \\
\text { (mais vulnerável, pois } \\
\text { pode ser distorcido por } \\
\text { fusões e aquisições), } \\
\text { lucro médio anual sobre } \\
\text { investimentos, aumen- } \\
\text { to médio do preço das } \\
\text { ações. }\end{array}$ & $\begin{array}{l}\text { Concluíram que a cul- } \\
\text { tura pode impactar no } \\
\text { desempenho em longo } \\
\text { prazo de uma organi- } \\
\text { zação, pois compro- } \\
\text { varam que culturas } \\
\text { que enfatizam todos } \\
\text { os interessados e que } \\
\text { possuem lideranças } \\
\text { fortes superam empre- } \\
\text { sas que não possuem } \\
\text { esses traços culturais. }\end{array}$ \\
\hline
\end{tabular}




\begin{tabular}{|c|c|c|c|c|}
\hline Autor & Título do Trabalho & Avaliação da cultura & $\begin{array}{l}\text { Avaliação do } \\
\text { desempenho }\end{array}$ & Conclusões \\
\hline $\begin{array}{l}\text { Ogbonna e Har- } \\
\text { ris, } 2000\end{array}$ & $\begin{array}{l}\text { Leadership style, } \\
\text { organizational cul- } \\
\text { ture and perfor- } \\
\text { mance empirical } \\
\text { evidence from UK } \\
\text { companies. }\end{array}$ & $\begin{array}{l}\text { A cultura organizacio- } \\
\text { nal foi classificada de } \\
\text { acordo com a tipologia } \\
\text { de Quinn (competitiva, } \\
\text { inovativa, burocrática } \\
\text { e de comunidade) e os } \\
\text { tipos de liderança con- } \\
\text { siderados foram: parti- } \\
\text { cipativa, instrumental } \\
\text { e suporte. }\end{array}$ & $\begin{array}{l}\text { O desempenho econô- } \\
\text { mico-financeiro de cur- } \\
\text { to prazo foi mensurado } \\
\text { por meio de questioná- } \\
\text { rio e de longo prazo foi } \\
\text { medido por dados de } \\
\text { satisfação de clientes, } \\
\text { aumento do volume de } \\
\text { vendas, fatia de merca- } \\
\text { do e diferença competi- } \\
\text { tiva. }\end{array}$ & $\begin{array}{l}\text { Inferiram uma relação } \\
\text { positiva entre desem } \\
\text { penho organizacional } \\
\text { e os tipos de cultura } \\
\text { competitiva e inovati } \\
\text { va e uma relação ne- } \\
\text { gativa entre os tipos } \\
\text { comunidade e buro- } \\
\text { crática. }\end{array}$ \\
\hline Sorensen, 2002 & $\begin{array}{l}\text { The strength of } \\
\text { corporate culture } \\
\text { and the reliabili- } \\
\text { ty of firm perfor- } \\
\text { mance }\end{array}$ & $\begin{array}{l}\text { Utilizou os dados de } \\
\text { pesquisa de Kotter e } \\
\text { Heskett (1994) sobre a } \\
\text { força da cultura corpo- } \\
\text { rativa. }\end{array}$ & $\begin{array}{l}\text { Analisou dados de re- } \\
\text { torno sobre investimen- } \\
\text { to (ROI) e fluxo de caixa } \\
\text { operacional entre } 1979 \\
\text { e } 1984 \text {. }\end{array}$ & $\begin{array}{l}\text { Concluiu que empre- } \\
\text { sas em ambientes es } \\
\text { táveis e com cultura } \\
\text { forte, o desempenho } \\
\text { é menos variável e em } \\
\text { ambientes voláteis de- } \\
\text { saparecem. }\end{array}$ \\
\hline Santos, 1998 & $\begin{array}{l}\text { Cultura e desem- } \\
\text { penho organiza- } \\
\text { cional: um estudo } \\
\text { empírico em em- } \\
\text { presas brasileiras } \\
\text { do setor têxtil. }\end{array}$ & $\begin{array}{l}\text { Aplicou um questio- } \\
\text { nário com } 24 \text { pro- } \\
\text { posições para gerar } \\
\text { perfis com diferentes } \\
\text { padrões conforme a } \\
\text { tipológica cultural de } \\
\text { Quinn. }\end{array}$ & $\begin{array}{l}\text { Baseou-se no trabalho } \\
\text { do Prof. Dante Matara- } \\
\text { zzo, que analisa índices } \\
\text { financeiros e econômi- } \\
\text { cos, utilizando dados de } \\
\text { 1988, } 89 \text { e } 90 .\end{array}$ & $\begin{array}{l}\text { Concluiu que a cultu- } \\
\text { ra está significativa- } \\
\text { mente associada ac } \\
\text { desempenho organi- } \\
\text { zacional eas empresas } \\
\text { com cultura forte pos- } \\
\text { suem melhor desem- } \\
\text { penho. }\end{array}$ \\
\hline
\end{tabular}

A tabela 11, na medida em que se permite ter uma visão ampla dos aspectos considerados pelos modelos estudados, possibilita uma breve comparação entre eles. Percebe-se que há uma predominância de estudos quantitativos para a análise da cultura e de dados econômico-financeiros na mensuração do desempenho de uma organização. Por exemplo, podese notar uma semelhança de tipo e meio de coleta de informação usada para análise de desempenho entre quase todos os estudos. A principal diferença entre deles esta na maneira como avaliam a cultura.
É possível notar que os diversos métodos de estudo da relação entre cultura e desempenho não mostram uma direção única. Muito embora os estudos representem esforços de entendimento dessa relação e apontem no sentido de haver uma relação entre a força da cultura organizacional de uma empresa e seu desempenho, o tema ainda carece de pesquisas que avaliem tais métodos, proponham novas abordagens para a análise qualitativa da cultura. 
O objetivo desse trabalho era propor, de forma sucinta, uma análise comparativa entre os principais modelos de estudo da relação entre cultura e desempenho organizacional existentes na literatura. Buscou-se se ater ao caráter descritivo dos modelos, sem que se entrasse em uma análise crítica sobre a eficácia dos mesmos, o que pode ser atribuído como sugestão para futuros trabalhos.
É relevante ainda citar que esse estudo não procurou entender o impacto da cultura sobre o desempenho de uma organização ou mesmo analisar a eficácia dos modelos estudados e sua legitimidade.

\section{REFERÊNCIAS}

BARNEY, J. B. Organizational culture: Can it be a source of sustained competitive advantage? Academy of Management Review, v.11, n.3, p.656-665, 1986.

CALORI, R.; SARNIN, P. Corporate Culture and Economic Performance: A French Study. Organization Studies, v. 12, n.1, p. 49-74, 1991.

CUMMINGS, T., WORLEY, C. Organizational Development and Change ( $7^{\text {th }}$ ed.). Cincinnati: South-Western, 2001

DEAL, T., KENNEDY, A. Corporate Culture: the Rites and Rituals of Corporate Life. Massachussets: Addison-Wesley, 1982.

DENISON, D.R. Bringing corporate culture to the button line. Organizational Dynamics, p. 4-22, 1984.

DENISON, D. R., MISHRA, A. K. Toward a Theory of Organizational Culture and Effectiveness. Organization Science, v.6, n.2, p.204-223, 1995.

DONNELY, R. The Interrelationship of Planning with Corporate Culture on Creation of Shared Values. Managerial Planning, v.32, mai-jun, 1984.

FREITAS, M. E. de. Cultura organizacional, grandes temas em debate. Revista de Administração de Empresas (RAE) da FGV; São Paulo, jul./set. 1991.

FREITAS, M. E. de. Cultura organizacional: formação, tipologias e impactos. São Paulo: Makron, McGraw-Hill, 1991.

GORDON, G. G. The relationship of corporate culture to industry sector and corporate perfomance. In: R.H. Kilmann, M. J. Saxton, R. Serpa and associate, gaining control of the corporate culture. San Francisco: Jossey-Bass, 1985. 
HOFSTEDE, G. etalli. Measuring Organizational Cultures: a Qualitative and Quantitative Study Across Twenty Cases. Administrative Science Quarterly, v.35, p.286-316, 1990.

KOTTER, J. P.; HESKETT, J. L. A cultura corporativa e o desempenho empresarial. São Paulo: Makron Books, 1994.

MARCOULIDES, G. A.; HECK, R. H. Organizational Culture and Performance: Proposing and Testing a Model. Organization Science, v.4, n.2, p. 209-225, 1993.

O'REILLY, C. A. III, CHATMAN, J., CALDWELL, D. People and organizational culture: a profile comparison approach to assessing person-organization fit. Academy of Management Journal, v.34, p.487-516, 1991.

OGBONNA, E.; HARRIS, L. C. Leadership style, organizational culture and performance: empirical evidence from UK companies. The International Journal of Human Resource Management, v. 11, n. 4, p. 766-788, 2000.

PETERS, T. J.; WATERMAN, R. H. Jr. In search of execellence. New York: Harper \& Row, 1982.

PETTIGREW, A. M. On Studying Organizational Cultures. Administrative Science Quarterly, v.24, n.4, p. 57081, 1979.

SANTOS, N. M. B. F. Cultura e desempenho organizacional: um estudo empírico em empresas do setor têxtil. Revista de Administração Contemporânea. Rio de Janeiro, v.2, n.1, p. 47-66, jan./abr. 1998.

SANTOS, N. M. B. F. Cultura organizacional e desempenho: pesquisa, teoria e aplicação. Lorena:;Stiliano, 2000.

SCHEIN, E. Guia de sobrevivência da cultura corporativa. Rio de Janeiro: Jose Olympio, 2001.

SCHEIN, E. Organizational culture and leadership: a dynamic view .San Francisco: Jossey Bass, 1985.

SORENSEN, J. B. The strength of corporate culture and the reliability of firm performance. Administrative Science Quarterly, v.47, n.1, p. 70-91, 2002.

1 Mestre em Administração, Pontifícia Universidade Católica de São Paulo - PUCSP.

2 Mestre em Administração, Pontifícia Universidade Católica de São Paulo - PUCSP. E-mail: fabiola@vetorial.net

3 Graduado em Engenharia Mecânica pela UNESP, Mestrando do Programa de Pós-Graduação em Administração - PUCSP. E-mail: r.bortoloto@ uol.com.br

Aceito em: 28 de abril de 2013

4 Professora Titular da Pontifícia Universidade Católica de São Paulo. Docente do Centro de Estudos Pós-Graduados - PUCSP. Programas de Administração e Ciências Contábeis. E-mail: admneusa@pucsp.br 